\title{
Soil Temperature and Physiological Response of Cotton to Alternate Partial Root-Zone Furrow Irrigation in the Oasis Field of Northwest China
}

\author{
Wang Zhenchang ${ }^{1,2, ~ *, ~ C h e n ~ S h e n g ~}{ }^{1,2}$, Wang Junyi ${ }^{1,2}$, Yu Yinglei ${ }^{2}$, Gao Yaxian ${ }^{2}$, Zhu Jianbin², \\ Cao Yü ${ }^{2}$, Lu Yangyang ${ }^{2}$ \\ ${ }^{1}$ Key Laboratory of Efficient Irrigation-Drainage and Agricultural Soil-Water Environment in Southern China, Ministry of Education, College \\ of Water Conservancy and Hydropower Engineering, Hohai University, Nanjing, China \\ ${ }^{2}$ College of Water Conservancy and Hydropower Engineering, Hohai University, Nanjing, China
}

\author{
Email address: \\ wangzhenchang@hhu.edu.cn (Wang Zhenchang), 165548159@qq.com (Wang Zhenchang) \\ ${ }^{*}$ Corresponding author
}

\section{To cite this article:}

Wang Zhenchang, Chen Sheng, Wang Junyi, Yu Yinglei, Gao Yaxian, Zhu Jianbin, Cao Yu, Lu Yangyang. Soil Temperature and Physiological Response of Cotton to Alternate Partial Root-Zone Furrow Irrigation in the Oasis Field of Northwest China. International Journal of Environmental Protection and Policy. Vol. 4, No. 6, 2016, pp. 162-170. doi: 10.11648/j.ijepp.20160406.12

Received: November 23, 2016; Accepted: December 2, 2016; Published: December 7, 2016

\begin{abstract}
The shortage of water resource severely affect the sustainability of the agricultural systems in the arid regions of China. Enhancing water use efficiency of irrigated agriculture is a high priority for agricultural improvement in China. Alternate Partial Root-zone Furrow irrigation (AFI) has been proved to be an effective water-saving irrigation method in the oasis field of northwest China, whereas the responses of soil temperature to AFI was seldomly studied. In this study, the field experiment was carried out in 2007 at Xuebai Experimental Station of Minqin Agricultural Extension Center of Gansu to study the changes of soil temperature as well as physiological responses of cotton to different irrigation regimes, i.e. alternate partial root-zone furrow irrigation (AFI, neighboring two furrows alternatively watered) and conventional furrow irrigation (CFI, all furrows watered) under plastic film mulching with the same irrigation level (24 mm for each irrigation). Results indicated that the differences of soil temperature of two neighboring furrows in AFI were significant $(P<0.05)$, the values of the drying furrow always being higher than those of the irrigated ones. The data also showed that when approaching the next irrigation cycle, both the two furrows in AFI had similar soil temperature at the depth of $0-25 \mathrm{~cm}$. Soil temperature difference between the irrigated and the drying furrows reached as high as $4{ }^{\circ} \mathrm{C}$ after irrigation, and decreased to almost $0^{\circ} \mathrm{C}$ at the end of the irrigation cycle. The difference of daily average soil temperature of ridge between AFI and CFI during the growing season was not apparent in the first and second irrigation cycle, whereas in the third and fourth irrigation cycle (approximately after the budding stage), the differences between them become significant $(P<0.05)$; there were significant positive linear relationships between $\mathrm{T}_{\mathrm{n}} / \mathrm{T}_{\mathrm{s}}($ the ratio of average soil temperature of north furrows and south furrows) and $\mathrm{SWC}_{\mathrm{w}} / \mathrm{SWC}_{\mathrm{d}}$ (the ratio of average $\mathrm{SWC}$ of irrigated furrows and the drying ones) $\left(\mathrm{R}^{2}=0.703, P<0.01\right)$; The WUE-A/WUE-C(the ratios of WUE of AFI and CFI) were more than 1.0 in the first few days after irrigation, whereas at the end of the irrigation cycle, the value declined to be the lowest (0.75); There was no significant difference for the seed cotton yield of AFI and CFI, whereas the percentages of pre-frost seed cotton of AFI was significant higher than that of CFI $(P<0.05)$. This study could provide valuable data for the implement of AFI in the oasis field of northwest China.
\end{abstract}

Keywords: Cotton, Alternate Partial Root-Zone Furrow Irrigation, Soil Temperature, Soil Water Content

\section{Introduction}

The shortage of water resource severely affect the sustainability of the agricultural systems all over the world, which is especially true in the arid and semi-arid regions of China [1]. Enhancing water use efficiency both under rain fed and irrigated agriculture is a high priority for agricultural improvement in China [2]. As irrigation of agricultural lands accounts for over $85 \%$ of water usage worldwide [3], even a 
minor reduction in irrigation water could substantially increase the water available for other purposes. This is certainly true for the situation in the Hexi Corridor of Northwest China because the ground water table is falling steadily year by year and environmental deterioration is intensifying [4]. The increased competition between agriculture, industry and tourism as well as low water use efficiency (WUE) in irrigated agriculture are forcing growers in the Hexi Corridor to adopt new irrigation methods and cultivation practices to use water more judiciously and increase irrigation WUE [4]. In order to attain this aim, various irrigation methods, such as limited irrigation, non-full irrigation, deficit irrigation (DI), and alternate partial rootzone drying dirrigation (APRI) have been recommended in arid and semi-arid area of China [1] [2] [3] [5] [6]. DI is a method that irrigates the entire root zone with an amount of water less than the potential evapotranspiration, and the mild stress has minimal effects on the yield [6]. APRI is a further refinement of DI; It involves alternately irrigating only one part of root system, leaving the dry part of the rootzone to generate root-to-shoot signals to suppress crop water use [7] [8]. Previous studies have demonstrated that APRI could save considerable irrigation amount [7] [8] [9] [10] [11] [12] [13] [14], and shifting of irrigation between different sides of APRI plants has been considered to be critical to maintain a continuous ABA signaling and to reduce plant water use [14]. Without shifting of irrigation in APRI-treated plants, the ABA signal could be diminished and $g_{s}$ could return to the value of the FI plants [15]. Continuous monitoring of soil moisture could help irrigation managers to decide the suitable time to shift sides of APRI [16] [17] [18] [19]. Whereas continuous soil moisture content monitoring is a difficult, labour and time -cousuming practices for local farmers in the rural area, thus finding a quick and easy method to schedule the APRI irrigation is necessary.

Previous APRI studies focused on the uptake of $\mathrm{N}$ and $\mathrm{P}$ by plants, ABA concentration in the xylem sap, the population and distribution of microbia in the drying and wetting soil profiles as well as $\delta^{15} \mathrm{~N}$ in leaves [20] [21] [22] [23] [24] [25], but few reports focused on the changes of soil temperature in different root-zone [26]. Soil temperatures are one of the most important state variables of agroecosystems [26]. Temperature has significant impacts on physiological metabolism both in roots and shoots by influencing processes such as photosynthesis, respiration, ion and water uptake, and signal transduction [27]. APRI can lead to heterogeneous distribution of soil moisture [12], and thus may affect the soil temperature in different root-zone [27]. Previous studies have been conducted to assess the influence of different field practices and irrigation regimes on the changes of soil temperature in the root-zone or their effects on the growth of root systems [28] [29] [30], but few research studied the effects of APRI on the changes of soil temperatures as well as their relationships with physiological effects. The objective of the present experiment was to study the effects of APRI and DI, which having the same irrigation volume during the growing season, on the changes of soil temperature and physiological response during typical irrigation cycles. In addition, the relationships between soil water contents and soil temperatures in different root zone were also investigated.

\section{Materials and Methods}

\subsection{Experimental Site}

The field experiment was carried out in 2007 at Xuebai Experimental Station of Minqin Agricultural Extension Center of Gansu, the lower valley of Shiyang river basin in the oasis region between Tengger Desert and Badain Jaran Desert of northwest China $\left(38^{\circ} 05^{\prime} \mathrm{N}, 103^{\circ} 03^{\prime} \mathrm{E}\right.$, altitude $\left.1340 \mathrm{~m}\right)$. This experimental station is located at the typical continental temperate arid zone, with an average annual sunshine duration of more than $3010 \mathrm{~h}$, an annual accumulated temperature (higher than $10.8^{\circ} \mathrm{C}$ ) of more than $3148^{\circ} \mathrm{C}$, a mean annual precipitation of $110 \mathrm{~mm}$ and a mean annual pan evaporation is $2644 \mathrm{~mm}$. The groundwater table depth is consistently below 13-18 m. The topsoil, a sandy loam with a moderate organic matter content, has a moderate permeability. The bulk density and field capacity of the the upper $1.0 \mathrm{~m}$ of the soil profile is approximately $1.4 \mathrm{~g} \cdot \mathrm{cm}^{3}$ and $0.25 \mathrm{~cm}^{3} \cdot \mathrm{cm}^{-3}$, respectively.

\subsection{Experimental Design}

Two furrow irrigation methods, i.e. alternate partial root-zone furrow irrigation (AFI, neighboring two furrows alternatively watered) and conventional furrow irrigation (CFI, all furrows watered), were applied, which were all under plastic film mulching with the same irrigation level $(24 \mathrm{~mm}$ for each irrigation); The timing of irrigation strictly followed the local commercial practice and the amount of irrigation was about $30-50 \%$ of conventional furrow irrigation water amount in the local planting practice in 2007 (detailed information in Table 1). The field experiment had totally 6 plots, arranged in a randomized block design with three replicates per treatment. Each plot area was $90 \mathrm{~m}^{2}(6 \mathrm{~m} \times 15 \mathrm{~m})$, with one furrow ditch between two neighboring plots to prevent the lateral movement of irrigation water. Irrigation amount was controlled by a flow meter installed on the gated plastic pipes. Fertilizer was applied and mixed using $\left(\mathrm{NH}_{4}\right)_{2} \mathrm{HPO}_{4}$ at 225 $\mathrm{kghm}^{-2}$ and $\mathrm{Ca}\left(\mathrm{H}_{2} \mathrm{PO}_{4}\right)_{2}$ at $450 \mathrm{~kg} \mathrm{hm}^{-2}$ in the same topsoil. Cotton seeds were sown on on May $1^{\text {st }}$ ( 0 Days after sowing, 0 DAS). All the cotton managements except for the irrigation were the same during the whole growing season. Details of the meteorological data during cotton growth stage in 2007 were shown in [43].

Table 1. Details of irrigation treatment on cotton growth in the oasis field in 2007.

\begin{tabular}{llll}
\hline $\begin{array}{l}\text { Irrigation } \\
\text { treatment }\end{array}$ & $\begin{array}{l}\text { Irrigation } \\
\text { Times }\end{array}$ & $\begin{array}{l}\text { Irrigation } \\
\text { Amount }\end{array}$ & Irrigation date \\
\hline & & (mm/irrigation) & (Month/Day) \\
\hline AFI & 4 & 24 & $06 / 20,07 / 15,07 / 30$, \\
CFI & 4 & 24 & $08 / 15$ \\
\hline
\end{tabular}




\subsection{Soil Water Measurement}

To determine the distribution of soil water content (SWC), two PVC access tubes in both furrow ditches and one $1.0 \mathrm{~m}$ tube in the ridge were installed for each plot. SWC was measured at 7 days intervals using a portable soil moisture monitoring system (Diviner 2000, Sentek Pty Ltd., Australia). In addition, for monitoring the day-to-day changes of soil water content, measurement was conducted at 8:00 local time after each irrigation for about 10 days (raining days were not included). The vertical profile of soil water content in each tube was determined from measurements of soil water content at $0.1 \mathrm{~m}$ intervals. Readings were taken through the wall of a PVC access tube. The gravimetric sampling technique and steel rings were used to calibrate the Diviner 2000 display unit.

\subsection{Soil Temperature Measurement}

The central rows in the central of the plots and their neighboring furrows were used for soil temperature measurements. Soil temperature were measured by a set of thermometers at depths of $0.05,0.10,0.15,0.20,0.25 \mathrm{~m}$ below the surface of the furrows and the ridges at morning (8:00), afternoon (14:00) and night (20:00) on every day of the growing seasons (raining days were not included). In this study, the average soil temperatures of the five depths were used. At the same point of the transect, soil water contents of the $0-0.3 \mathrm{~m}$ depth were also measured using PVC tubes. Data of soil water content and soil temperature were simultaneously collected.

\subsection{Physiological Measurements and Sampling}

For monitoring the daily changes of photosynthesis rate $\left(\mathrm{P}_{\mathrm{n}}\right)$, transpiration rate $\left(\mathrm{T}_{\mathrm{r}}\right)$ and Water use efficiency (WUE, calculated as $\mathrm{P}_{\mathrm{n}} / \mathrm{T}_{\mathrm{r}}$ ), four youngest mature leaves of each treatment, which were fully expanded, were chosen for the measurement by a portable photosynthesis system (ADC Bio-Scientific Ltd., UK) at 11:00-13:00h local time during sunny and cloudless days (from August 5 to August 14 in 2007).

Plant vegetative growth was quantified by measuring the increment of plant height and the changes of Leaf Area Index (LAI). Eight plant height at center rows were monitored at each plot every 7 days. The LAI of cotton plant were measured by PAR/LAI Ceptometer (AccuPAR model LP-80, Decagon Devices, Inc.) at center rows of each plot during different growing stages. The numbers of bud, flower and boll were also counted every 7 days on 10 plants at the center row of each plot. For yield (seed cotton) assessment, blocks $(2 \mathrm{~m} \times 2$ $\mathrm{m})$ at the center of each plot were sampled and harvested by hand-picking following local commercial practice of harvesting times.

\subsection{Statistical Analysis}

Data were analyzed by one-way analysis of variance (ANOVA). When it was necessary the data were transformed to assure ANOVA assumptions. Pearson correlations was conducted to determine the relationship between soil temperature and soil water content. All statistical analyses were performed using the SPSS 13.0 statistical package (SPSS Inc., Chicago, USA).

\section{Results}

\subsection{Soil Water Dynamics}

Changes of SWC in the irrigated and drying furrows during the experimental periods of AFI in the top soil was presented in Fig. 1: the SWC between the two neighboring furrows in AFI remained different until the next irrigation, with higher SWC in the previously irrigated furrows. This pattern of soil water distribution in the cotton root-zone could allow part of the root system to be always exposed to drying soil. For CFI treatment, the SWC of two neighboring furrows in the depth of $0-30 \mathrm{~cm}$ increased and dropped simultaneity as for the rain, irrigation and evaportranspiration (Fig. 2). The SWC of irrigated furrow increased dramatically after the irrigation on July 15th, whereas it was also found that the SWC of the non-irrigated furrows was relatively constant or rose slightly in the following days after irrigation. As for the SWC of AFI in the depth of $40-70 \mathrm{~cm}$, it was found that the difference between the neighboring furrows was relatively smaller than that of $0-30 \mathrm{~cm}$ (Fig. 3). In general, the effect of partial wetting of the root zone was more apparent in the upper layer than that in the depth of $40-70 \mathrm{~cm}$. Temporial changes of average soil water content at $40-70 \mathrm{~cm}$ soil profile in CFI were almost the same during the irrigation cycle (data not shown).

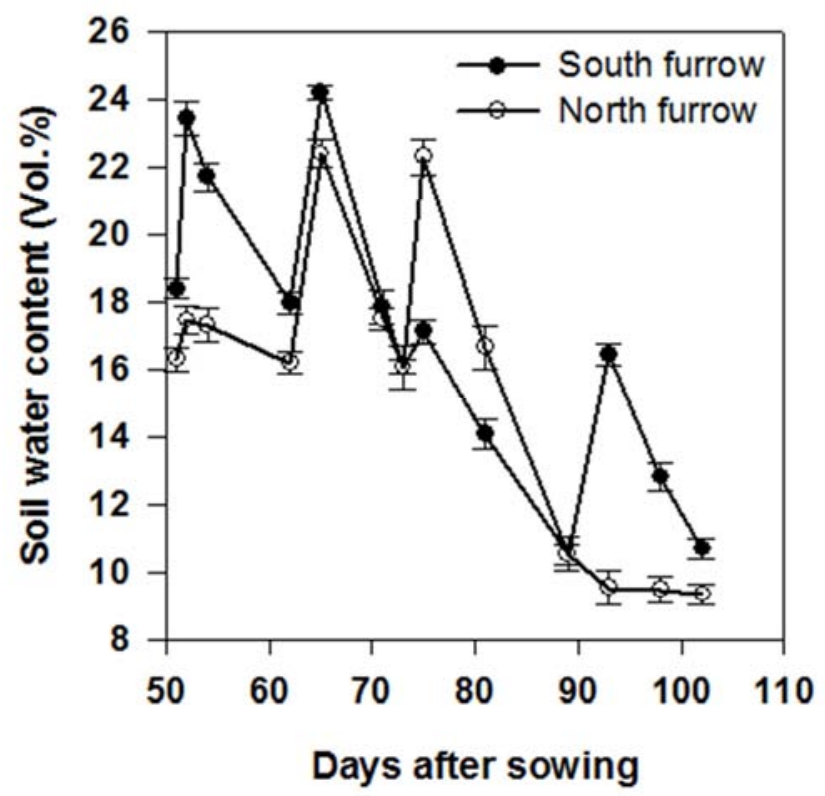

Figure 1. Changes of soil water content (volume) at the depth of $0-30 \mathrm{~cm}$ in different furrows during the growing stage of cotton in the treatment of AFI. 


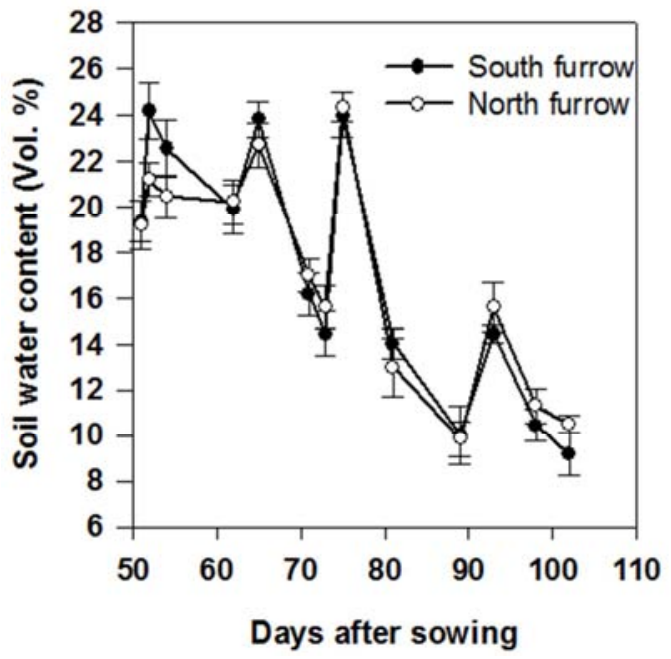

Figure 2. Changes of soil water content (volume) at the depth of $0-30 \mathrm{~cm}$ in different furrows during the growing stage of cotton in the treatment of CFI.

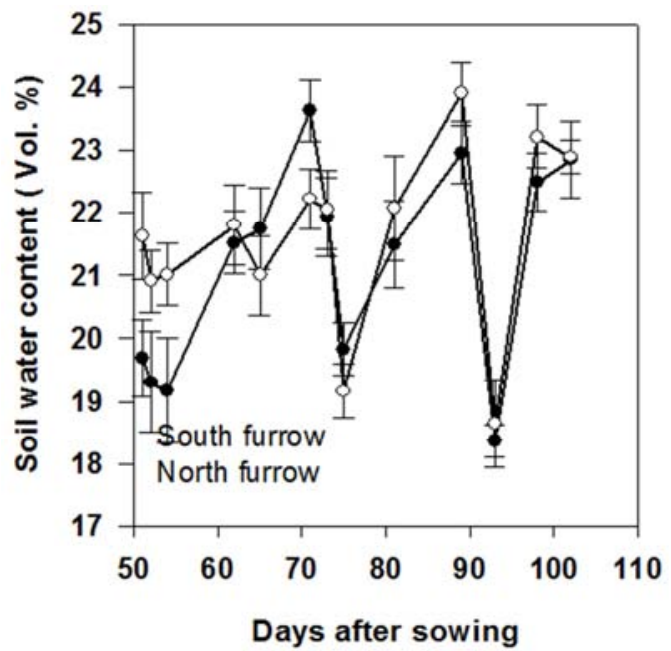

Figure 3. Changes of soil water content (volume) at the depth of $40-70 \mathrm{~cm}$ in different furrows during the growing stage of cotton in AFI.

\subsection{Soil Temperature Dynamics}

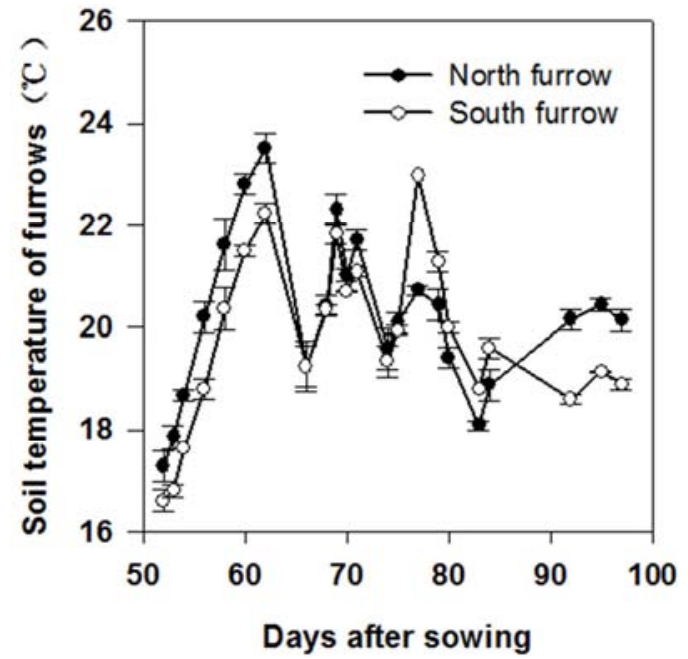

Figure 4. Changes of soil temperature of furrows at the depth of $0-25 \mathrm{~cm}$ during the growing stages of cotton in the treatments of AFI.

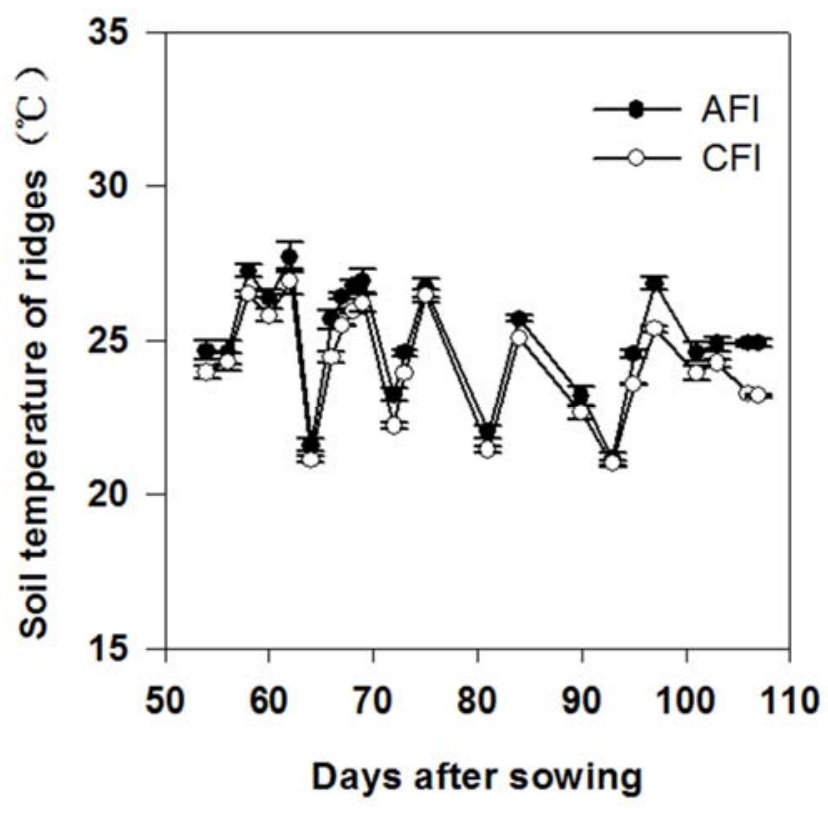

Figure 5. Changes of soil temperature of ridges at the depth of $0-25 \mathrm{~cm}$ during the growing stages of cotton in the treatments of AFI and CFI.

Soil temperatures measurements started on June $20^{\text {th }}, 2007$. (Changes of average soil temperature of AFI in the depth of $0-25 \mathrm{~cm}$ of the irrigated and drying furrows during the experimental periods were shown in Fig. 4. It showed that the differences of soil temperature of two neighboring furrows were significant $(P<0.05)$, the values of the drying furrow always being higher than those of the irrigated ones. The data also showed that when approaching the next irrigation, all the two furrows in AFI had similar soil temperature at the depth of $0-25 \mathrm{~cm}$.

As shown in Fig. 4, the differences of soil temperature between the two adjacent furrows in AFI reached their maximums following irrigation and then declined towards the next irrigation: the soil temperature difference between the irrigated and the drying furrows reached values as high as $4^{\circ} \mathrm{C}$ after irrigation, and decreased to almost $0^{\circ} \mathrm{C}$ at the end of the irrigation cycle. As demonstrated in Fig. 5, the difference of daily average soil temperature of ridges between AFI and CFI during the growing season was not apparent in the first and second irrigation cycle, while in the third and fourth irrigation cycle, the differences between them become significant.

To find the correlation between soil temperature and SWC as well as to eliminate the effects of weather condition, the relationships between $T_{n} / T_{s}$ (the ratio of average soil temperature of north furrows and south furrows) and $\theta_{\mathrm{w}} / \theta_{\mathrm{d}}$ (the ratio of average SWC of irrigated furrows and the drying ones) was plotted in Fig. 6. From Fig. 6 we could see that there was a significant positive linear relationships between $\mathrm{T}_{\mathrm{n}} / \mathrm{T}_{\mathrm{s}}$ and $\theta_{\mathrm{w}} / \theta_{\mathrm{d}}\left(\mathrm{R}^{2}=0.703\right.$, $P<0.01)$. 


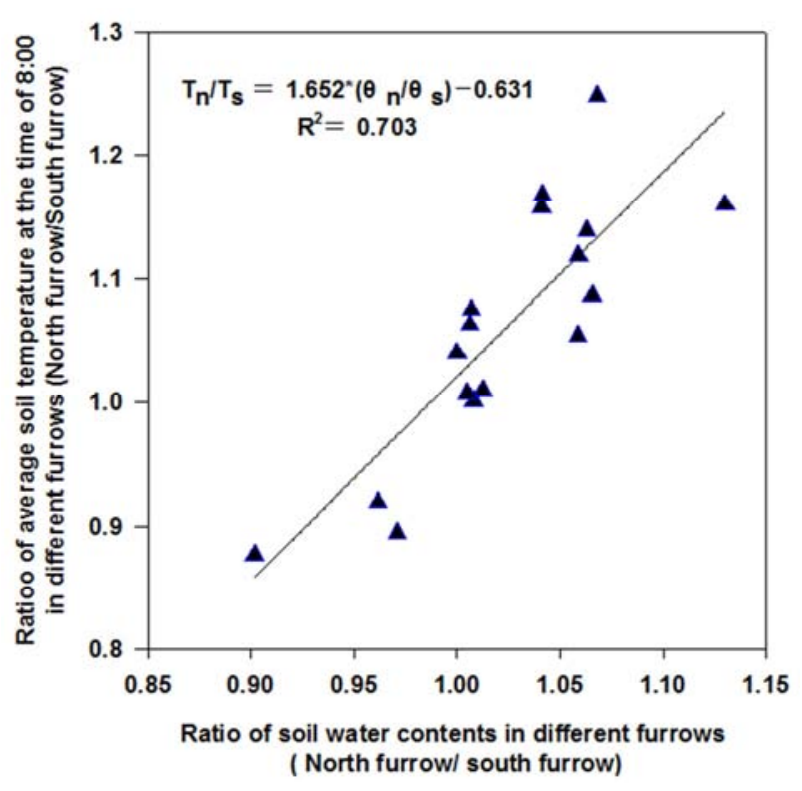

Figure 6. Correlation between ratios of average soil temperature $(0-25 \mathrm{~cm})$ at 8:00 and ratios of soil water contents in different furrows.

\subsection{Physiological Responses of Cotton}

Changes of $\mathrm{T}_{\mathrm{r}}-\mathrm{A} / \mathrm{T}_{\mathrm{r}}-\mathrm{C}$ (the ratios of $\mathrm{T}_{\mathrm{r}}$ of $\mathrm{AFI}$ and $\mathrm{CFI}$ ), $\mathrm{P}_{\mathrm{n}}-\mathrm{A} / \mathrm{P}_{\mathrm{n}}-\mathrm{C}$ (the ratios of $\mathrm{P}_{\mathrm{n}}$ of $\mathrm{AFI}$ and $\left.\mathrm{CFI}\right)$ and WUE-A/WUE-C (the ratios of WUE of AFI and CFI) in an irrigation cycle were shown in Fig. 7. The $\mathrm{T}_{\mathrm{r}}-\mathrm{A} / \mathrm{T}_{\mathrm{r}}-\mathrm{C}$ was about 1.0 on 4 days before the third irrigation, which indicated that CFI having similar stomatal conductance with that of AFI at the end of the last irrigation cycle. With the days after irrigation increased, $\mathrm{T}_{\mathrm{r}}-\mathrm{A} / \mathrm{T}_{\mathrm{r}}-\mathrm{C}$ declined to approximately 0.80 and 0.60 on 4 and 8 days after the third irrigation, which indicated that AFI had lower $T_{r}$ value than that of CFI in the first few days during an irrigation cycle. Whereas, $\mathrm{T}_{\mathrm{r}}-\mathrm{A} / \mathrm{T}_{\mathrm{r}}-\mathrm{C}$ was approaching 1.0 by the end of irrigation cycle, which was contributed by the equivalent or lager $\mathrm{g}_{\mathrm{s}}$ of AFI than CFI (data not shown). As indicated in Fig. 7, $\mathrm{P}_{\mathrm{n}}-\mathrm{A} / \mathrm{P}_{\mathrm{n}}-\mathrm{C}$ fluctuated around 1.0, which indicated that during the third irrigation cycle the $\mathrm{P}_{\mathrm{n}}$ of AFI and CFI were fairly the same. The WUE-A/WUE-C were higher than 1.0 in the first few days after irrigation, whereas at the end of the irrigation cycle, the value declined to be the lowest $(0.75)$.

\subsection{Growth and Yield Responses of Cotton}

Growth response of cotton were quantified by plant heights and leaf areas. From Fig. 8, we could see that, during the early growing stage, there were no significant differences for LAI. After the budding stage (June 30 in 2007, 61DAS), compared with CFI, AFI significantly reduced the LAI values, which was in agreement with the situation for heights (Fig. 9). The heights of AFI were almost the same with those of CFI before the budding stage. Whereas, after budding stages, plant heights of AFI were significantly inhibited than their counterparts (CFI). There was no significant differentce for the seed cotton yield of AFI and CFI, whereas the percentages of pre-frost seed cotton of AFI was significant higher than that of CFI (Fig. 10).

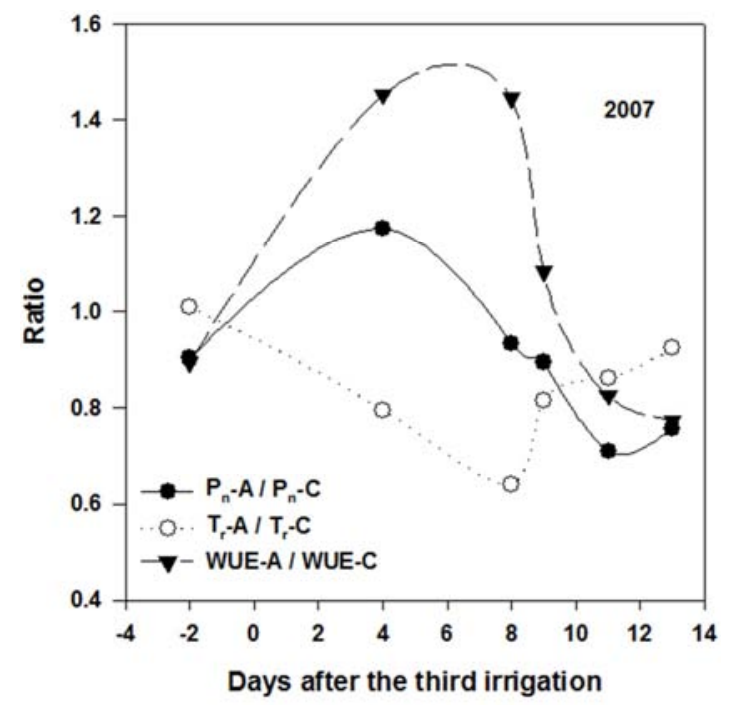

Figure 7. Changes of ratio of Pn in the treatment of AFI to CFI as well as $T_{r}$ and WUE during the growing stage of cotton.

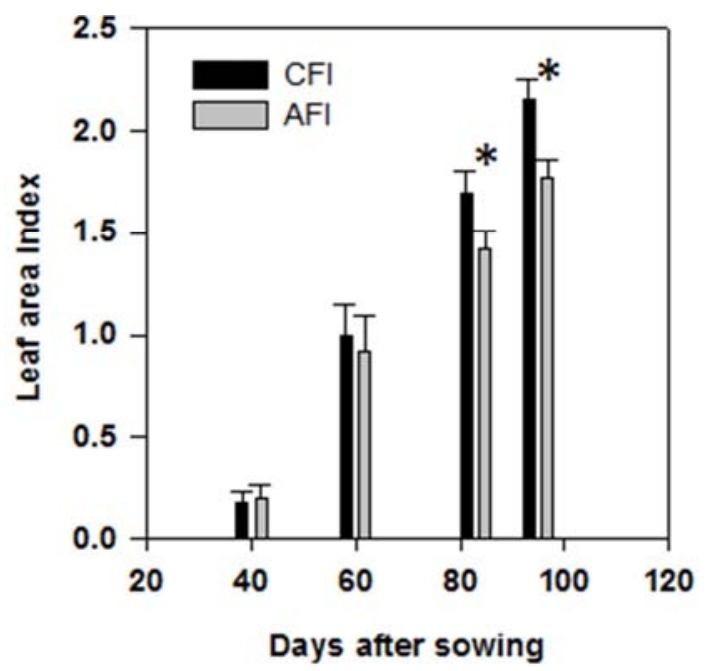

Figure 8. Leaf area index of different time in the growing period of cotton. Bars indicate $\pm S . E(n=3)$. * indicates significant differences between $C F I$ and AFI treatment.

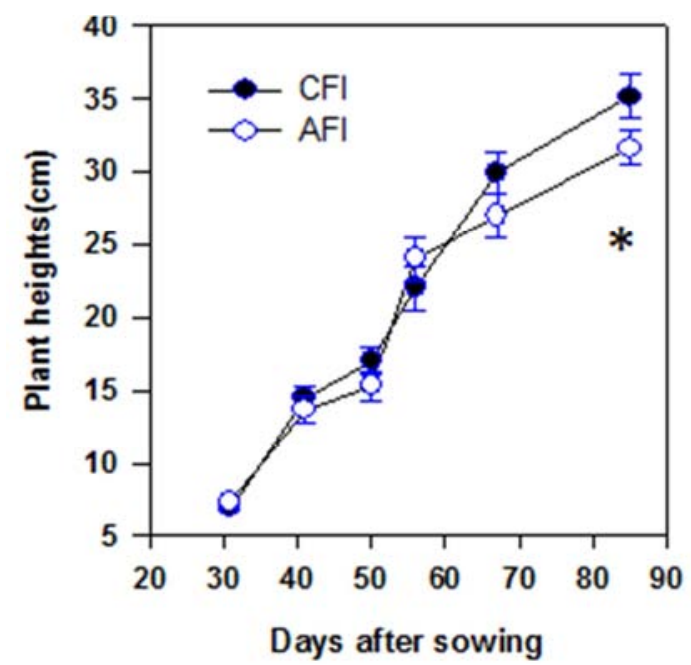

Figure 9. Plant heights of different time in the growing period of cotton. Bars indicate $\pm S . E(n=10)$. * indicates significant differences between CFI and AFI treatment. 




Figure 10. Accumulated yield of seed cotton and percentages of pre-frost seed cotton. Bars indicate $\pm S . E .(n=3) . *$ indicates significant differences between CFI and AFI treatment.

\section{Discussion}

APRI is an irrigation method which could maintain a reasonable crop yield as well as saving irrigation amount [1] [5] [8] [17]. It has been proved to be an effective irrigation way for many crops and in many areas [12] [44] [45] [46] [47]. However, many of the studies compared APRI and conventional irrigation (CI or DI) on crop yield and WUE with different irrigation amount (the irrigation amount of APRI was about $50 \%$ of $\mathrm{CI}$ ), assuming that APRI was responsible for observed differences, but ignoring the possible effect of reduced irrigation ( $\mathrm{Gu}$ et al., 2004). A review published in 2009 found that the yield per unit applied irrigation water of crops under APRI was significantly $(P=0.007)$ but modestly (5\%) higher than their counterparts with CI where both received similar amounts of irrigation [31]. Considering the cost and manage complexity of implementing APRI, it is critical to identify the rare conditions where this method could be economically justified [31]. Whereas in Northwest China, because only furrows were used for the application of AFI and there were not much field practices and labor costs were needed for such an irrigation method, AFI might be a feasible irrigation method for the rural area [32]. The pattern of APRI are usually that approximately half of the root system should be always exposed to drying soil while the remaining half is irrigated frequently as in full irrigation, whereas for the consideration of the frequency of furrow irrigation could not be too high in the field, one part of root system in AFI could not always be kept in full irrigated in terms of water extraction. From Fig. 1 we could see that there were significant differences between SWC of the irrigated furrow and un-irrigated immediately after irrigation in the treatment of AFI, whereas with the days after irrigation increased, the differences between them gradually diminished. From Fig. 1 and Fig. 3, we could also conclude that AFI induced expected differences in SWC only could be found in the top soil layer(0-30 cm depth), whereas the difference of SWC in the depth of $40-100 \mathrm{~cm}$ was not significant, which is in agreement with the findings by Du et al. [33]

The core of AFI is alternating irrigation in space and time to generate wet-dry cycles in different sections of the root system [12]. It is thus necessary to change the wet and dry parts of the root-zone during APRI regularly with the aim at maintaining a supply of soil drying-induced root-to-shoot signals from the drying root system to suppress crop water use as well as keeping the other side of root system full irrigated to keep the leaves hydrated [5] [8] [20] [34]. We hypothesized that if there was any chemical signaling trigged by the drying root-zone system in APRI plants, there should be an early stomatal closure and therefore, an early decline in transpiration rate in APRI-treated plant than CFI immediately after irrigation [34] [35] [36]. In agreement with this, in our study, $T_{r}$ of AFI was significantly lower than that of CFI immediately after irrigation (Fig. 7). To the opposite, $\mathrm{P}_{\mathrm{n}}$ of AFI and CFI did not show the same trend with those of $T_{r} . P_{n}$ of AFI and CFI were fairly the same, and consequently, the WUE of AFI were higher than that of CFI immediately after irrigation, but there was no significant difference for WUE between CFI and AFI at the end of the irrigation cycle (Fig. 7). This may be explained by the following reasons: immediately after irrigation, in CFI, water was well applied evenly to two sides of root system in the top soil, whereas in AFI, only one side of root system was well irrigated, and the other part of root system was in drying soil. Stomatal responses depend on signal production by root in contact with drying soil and signal transmission to the shoot, which depending on the fraction of sap flow from different parts of the root system [36]. Immediately after irrigation, for the same whole SWC availability, ABA concentration in leaves of APRI was higher than that of CFI plants with moderate soil drying [25]. Lower leaf ABA in the treatment of CFI may result in higher stomatal conductance, thus higher value of $\mathrm{T}_{\mathrm{r}}$. At the end of the irrigation cycle, for AFI, when the SWC falls below a threshold, the sap flow from the roots in drying soil may cease or much less than that from wet root zone, resulted in the lower ABA concentration in the treatment of AFI than that of CFI [25], and Consequently resulted in the similar $T_{r}$ values and WUE for both treatments. In practice, in the absence of rainfall, SWC in drying furrow decreased continuously during a furrow irrigation cycle (Fig. 1). Thus in order to successfully implementation of AFI, preventing the dry side becoming too 
dry, and alternating irrigation in the proper time is necessary [35].

Soil temperatures are one of the most important state variables of agroecosystem. Soil temperature had more dramatic effects on root elongation than bulk density, moisture content, or soil aeration [37] [38] [39] [40]. Recently study reported that xylem sap ABA concentration of plant increased with the increase of root temperature [42]. Soil temperatures could be influenced by irrigation practices, with non-irrigated soil having higher soil temperature than the irrigated ones on hot days [41]. In this experiment, there was significant difference of soil temperature in ridges between AFI and CFI from 80 DAS, for which the irrigation amounts were the same (Fig. 5). This result may be explained by a number of reasons. First, in the CFI treatment, both furrows of the cotton were irrigated, much more water was infiltrated to the ridge than that of AFI. As for the same type of soil, higher soil water content means lower soil thermal conductivity [26] [29] [30]. Another reason for the different soil temperatures of ridges under different irrigation regimes might be related to the better control of the excessive vegetative growth, and the larger amount of light reaching the surface area of root zone in AFI than CFI. Tang et al. found that plant leaf size and height were less in PRI plants than in conventional irrigated canopy [32]. $\mathrm{Du}$ et al. found that less irrigation level in AFI certainly inhibits the growth of cotton plant if compared to that of CFI [33]. In agreement with this, in our study, for the early date, there were no significant differences between the LAI of AFI and CFI (Fig. 8). After the budding stage (June 30 in 2007), the AFI significantly reduced the LAI compared with CFI. The plant heights of the AFI treatment were also lower than those of CFI, but not significant. Collectively, in our study, the LAI and heights in the treatment of AFI were significant lower than those of CFI in the late growing season (Fig. 8 and Fig. 9), thus reducing the canopy density, altering microclimate in the canopy, increasing the amount of light reaching the surface area of root-zone, and consequently increasing the soil temperature. In our study, AFI treatment had significant higher pre-frost seed cotton rate than that of CI (Fig. 10), which might be related to the increased xylem sap ABA concentration and ethylene [42] under higher soil temperature in the treatment of AFI than that of CFI (Fig. 5).

Soil water content and soil temperature was monitored for its temporal and spatial variations in different furrow in AFI (Fig. 1, Fig. 2, Fig. 3, Fig. 4 and Fig. 5). The result showed that AFI provide a completely different soil moisture environment and soil temperature environment for different side of root system: root systems in the drying state having higher soil temperature while the remainder in a wet state with lower soil temperature, which is in agreement with the founding of Morote et al. and Oliveira et al. [41]. The significant positive linear correlation betwieen $\mathrm{T}_{\mathrm{n}} / \mathrm{T}_{\mathrm{s}}$ and $\theta_{\mathrm{w}} / \theta_{\mathrm{d}}$ in Fig. 6 could be related to different soil thermal conductivity [26] [29] [30]. As for the same type of soil, soil water content is a major fact that influence the soil thermal conductivity. The irrigated furrow had higher soil water content and resulted in a higher thermal conductivity. In this experiment, in AFI, with one part of root system always being kept in a drying state while the remainder was functional in terms of water extraction, not always be kept full irrigated, when the soil water content of the irrigated furrow and non-irrigated furrow approach the same at the end of one irrigation cycle, the effects of APRI diminished, and we could see that at that time, the $\mathrm{WUE}_{\text {leaf }}$ of AFI was similar or even smaller than those of CFI (Fig. 7). Because the close relationships between SWC and soil temperature (Fig. 6) as well as the measurement of soil temperature is an relatively easier and quicker than than that of SWC, It might be possible to use soil temperature as an index to schedule the AFI treatment.

\section{Conclusion}

In AFI, the drying furrows always showed significant higher soil temperature than those of the irrigated ones $(P<0.05)$ immediately after irrigation, but the differences gradually decreased to almost $0^{\circ} \mathrm{C}$ at the end of the irrigation cycle. The difference of daily average soil temperature of ridges between AFI and CFI during the growing season was not apparent in the first and second irrigation cycle, whereas for the third and fourth irrigation cycle, the differences between them became significant $(P<0.05)$; There were significant positive linear relationships between $T_{n} / T_{s}$ (the ratios of average soil temperature of north furrows and south furrows) and $\theta_{\mathrm{w}} / \theta_{\mathrm{d}}$ (the ratios of average $\mathrm{SWC}$ of irrigated furrows and the drying ones) $\left(\mathrm{R}^{2}=0.703, P<0.01\right)$; The WUE-A/WUE-C(the ratios of WUE of leaves for AFI and CFI) were higher than 1.0 in the first few days after irrigation, whereas at the end of the irrigation cycle, the value declined to be the lowest $(0.75)$; There were no significant differences for the seed cotton yield of AFI and CFI, whereas the percentage of pre-frost seed cotton of AFI was significant higher than that of $\mathrm{CFI}(P<0.05)$. This study could provide valuable data for the implement of AFI in the oasis field of northwest China.

\section{Acknowledgment}

We are grateful for Grants from National Key Research and Development Program of China during the 13th Five-Year Plan Period (2016YFC0400208), National Natural Science Foundation of China [51309080], the Fundamen-tal Research Funds for the Central Universities (2013B06014), and Water Conservancy Science and Technology Project of Jiangsu Province.

\section{References}

[1] Kang S Z. Towards water and food security in China. Chinese Journal of Eco-Agriculture, 2012, 22 (8): 880-885 (In Chinese with english abstract).

[2] Deng Xiping, Shan Lun, Zhang Heping, Turner Neil C. Improving agricultural water use efficiency in arid and semiarid areas of China. Agricultural Water Management 2006; 80: $23-40$. 
[3] Van Schilfgaarde J. Irrigation - a blessing or a curse. Agric Water Manage 1994; 25: 203-232.

[4] Su Xiaoling, Kang Shaozhong, Tong Ling. A dynamic evaluation method and its application for the ecosystem service value of an inland fiver basin: A ease study on the Shiyanghe River Basin in Hexi Corridor of Gansu Province. Acta Ecologica Sinica, 2006, 26 (6): 2011-2019.

[5] Kang S, Zhang J, Liang Z, Hu X, Cai H (1997) Controlled alternate partial rootzone irrigation: a new approach for water saving regulation in farmland. Agri Res Arid Areas 15: 1-6.

[6] English, M. and Raja, S. N., 1996. Perspectives on deficit irrigation. Agric. Water Manage. 32, pp. 1-14.

[7] Kang S, Liang Z, Pan Y, Shi P, Zhang J (2000) Alternate furrow irrigation for maize production in an arid area. Agric Water Manag 45: 267-274.

[8] Stoll M, Loveys B, Dry P (2000) Hormonal changes induced by partial rootzone drying of irrigated grapevine. Journal of Experimental Botany 51, 1627-1634. doi: 10.1093/jexbot/51.350.1627.

[9] Kang S, Zhang L, Hu X, Li Z, Jerie P (2001) An improve water use efficiency for hot pepper grown under controlled alternate drip irrigation on partial roots. Sci Hortic 89:257-267.

[10] Kang S, Hu X, Goodwin I, Jerie P (2002) Soil water distribution, water use, and yield of response to partial root zone drying under a shallow groundwater table condition in a pear orchard. Sci Hortic 92: 277-291.

[11] Kirda C, Cetin M, Dasgan Y, Topcu S, Kaman H, Ekici B, Derici MR, Ozguven AI (2004) Yield response of greenhouse grown tomato to partial root drying and conventional deficit irrigation. Agric Water Manage 69: 191-202.

[12] Kang S, Zhang J (2004) Controlled alternate partial root-zone irrigation: its physiological consequences and impact on water use efficiency. J Exp Bot 55: 2437-2446.

[13] Loveys, B. R., 2000. Using irrigation management to improve the water use efficiency of horticultural crops. Land Manage. 1 (3), 31-33.

[14] Dodd I. C. (2007) Soil moisture heterogeneity during deficit irrigation alters root-to-shoot signalling of abscisic acid. Functional Plant Biology 34, 439-448.

[15] Dodd IC, Egea G, Davies WJ. 2008. ABA signalling when soil moisture is heterogeneous: decreased photoperiod sap flow from drying roots limits ABA export to the shoots. Plant. Cell and Environment 31, 1263-1274.

[16] Davies, W. J., Bacon, M. A., Thomption, D. S., Sobeih, W., Gozalez-Rodriguez, 1., 2000. Regulation of leat and fruit growth in plants growing in drying soil: exploitation of plants' chemical signaling efficiency of water use in agriculture. J. Exp. Bot. 51, 1617-1626.

[17] Zegbe-Dominguez, J. A., Behbouidan, M. H., Lang, A., Clothier, B. E., 2003. Deficit irrigation and partial rootzone drying maintain fruit dry mass and enhance fruit quality in 'Petopride' processing tomato (licopersicon esculentum, Mill.). Scientia Hort. 98, 505-510.

[18] Antolin MC, Ayari M, Sanchez-Diaz M.2006. Effects of partial rootzone drying on yield, ripening and berry ABA in potted Tempranillo grapevines with split roots. Australian Journal of
Grape and Wine Research 12, 13-20.

[19] Gu, S., Guoqiang, D., Zoldoske, D., Hakim, A., Cochran, R., Fugelsang, K., Jorgensen, G., 2004. Effects of irrigation amount on water relations, vegetative growth, yield and fruit composition of Sauvignon blanc grapevines under partial root-zone drying and conventional irrigation in the San Joaquin Valley of California, USA. J. Hort. Sci. Biotechnol. 79, 26-33.

[20] Sadras VO (2009) Does partial root-zone drying improve irrigation water productivity in the Weld? A meta-analysis. Irri Sci 27: 183-190.

[21] Hu T, Kang S, Li F, Zhang J. 2009. Effects of partial rootzone irrigation on the nitrogen absorption and utilization of maize. Agr Water Manage. 96: 208-214.

[22] Liu, C. X., Rubœk, G. H., Liu, F. L., Andersen, M. N., 2015. Effect of partial root zone drying and dificit irrigation on nitrogen and phosphorus uptake in potato. Agric. Water Manag. $159,66-76$

[23] Wang Jinfeng, Hans de Kroon et al. Root foraging and yield component underlying limited effects of partial Root-zone Drying on oilseed rape, a crop with an indeterminate growth habit. Plant and Soil DOI 10.1007/s11104-009-9922-3.

[24] Wang Z, Liu F, Kang S, Jensen C R. 2012. Alternate partial rootzone drying irrigation improves nitrogen nutrition in maize (Zea mays L.) leaves. Environ Exp Bot. 75: 36-40.

[25] Dodd, Ian C. Measuring and modeling xylem ABA concentration ([X-ABA]) in tomato plants exposed to deficit irrigation (DI) and partial rootzone drying (PRD). Acta Horticulturae (2008), 792: 225-231.

[26] Karandish F, Shahnazari A. 2016. Soil temperature and maize nitrogen uptake improvement under partial root-zone drying irrigation. Pedosphere. 26 (6): 872-886.

[27] Allen DJ, Ort DR (2001) Impact of chilling temperatures on photosynthesis in warm climate plants. Trends Plant Sci 6: 36-42.

[28] McMichael B. L. and Burke J. J. (1994) Metabolic activity of cotton roots in response to temperature, Environ. Exp. Bot. 34, 201-206.

[29] Morote CGB, Vidor C and Mendes NG 1990. Soil temperature as affected by mulching and irrigation. Brazilian J. Soil Science $14,81-84$.

[30] Oliveira, J. C. M., Timm, L. C., Tominaga, T. T., Cássaro, F. A. M., Reichardt, K., Bacchi, O. O. S., Dourado-Neto, D., Camara, G. M., 2001. Soil temperature in a sugarcane crop as a function of the management system. Plant Soil 230, 61-66.

[31] Gu, S., Guoqiang, D., Zoldoske, D., Hakim, A., Cochran, R., Fugelsang, K., Jorgensen, G., 2004. Effects of irrigation amount on water relations, vegetative growth, yield and fruit composition of Sauvignon blanc grapevines under partial root-zone drying and conventional irrigation in the San Joaquin Valley of California, USA. J. Hort. Sci. Biotechnol. 79, 26-33.

[32] Tang LS, Li Y, Zhang JH (2005) Physiological and yieldresponses of cotton under partial rootzone irrigation. Field Crops Res 94: 214-223.

[33] Du Taisheng, Kang Shaozhong Zhang Jianhua.2006. Yield and physiological responses of cotton to partial root-zone irrigation in the oasis field of northwest China. Agricultural water management. 84(1-2):41-52. 
[34] Liu, F. L., Shahnazari, A., Andersen, M. N., Jacobsen, S. E., Jensen, C. R., 2006. Physiological responses of potato (Solanum tuberosum L.) to partial root-zone drying: ABA signalling, leaf gas exchange, and water use efficiency. J. Exp. Bot. 57, 3727-3735.

[35] Dodd IC, Theobald JC, Bacon MA, Davies WJ (2006) Alternation ofwet and dry sides during partial rootzone drying irrigation alters root-to-shoot signalling of abscisic acid. Functional Plant Biology 33, 1081-1089. doi: 10.1071/FP06203.

[36] Liu, F. L., Song, R., Zhang, X. Y., Shahnazari, A., Andersen, M. N., Plauborg, F., Jacobsen, S. E., Jensen, C. R., 2008. Measurement and modelling of ABA signalling in potato (Solanum tuberosum L.) during partial root-zone drying. Environ. Exp. Bot. 63, 385-391.

[37] Losdon S. D., Reneau R. B., Jr. and Parker J. C.(1987) Corn seeding root growth as in fluenced by soil physical properties. Agron. J. 79, 221.

[38] Wanjura D. F. and Buxton D. R. (1972) Hypocotyl and radicle elongation of cotton as affected by soil environment. Agron. J. 64, 431-434.

[39] McMichael B. L. and Quisenberry J. E. (1993) The impact of the soil environment on the growth of root ayatems, Environ. Exp. Bot. 34, 201-206.

[40] Macduff J. H., Wild A., Hopper M. J. and Dhanoa M. S.(1986) Effects of temperature on parameters of root growth relevant to nutrient uptake: measurements of oilseed rape and barley grown in flowing nutrient solution. Plant and Soil, 94(3):321-332.
[41] Morote CGB, Vidor C and Mendes NG 1990. Soil temperature as affected by mulching and irrigation. Brazilian J. Soil Science $14,81-84$.

[42] Zhang Y. P. QIAO Y. X. ZHANG Y. L. (2008). Effects of root temperature on leaf gas exchange and xylem sap abscisic acid concentrations in six Cucurbitaceae species PHOTOSYNTHETICA, 46 (3): 356-362.

[43] Wang Zhenchang, Du Taisheng, Yang Lei. (2008). Responses of cotton growth, yield and economic value to alternate furrow irrigation in desert oasis of Northwest China. Agricultural Research in the Arid Ateas, 26 (5): 84-89.

[44] Pérez-Pérez, J. G., Dodd, I. C., Botía, P., 2012. Partial rootzone drying increases water-use efficiency of lemon Fino 49 trees independently of root-to-shoot ABA signalling. Funct. Plant Biol. 39, 366-378, http://dx.doi.org/10.1071/ FP11269.

[45] Wang, Y. S., Liu, F. L., Jensen, C. R., 2012 Comparative effects of deficit irrigation and alternate partial root-zone irrigation on xylem $\mathrm{pH}, \mathrm{ABA}$ and ionic concentrations in tomatoes. J. Exp. Bot. 63, 1907-1917.

[46] Wang, Y. S., Liu, F. L., Jensen, C. R., 2012. Comparative effects of partial root-zone irrigation and deficit irrigation on phosphorus uptake in tomato plants. J. Hortic. Sci. Biotechnol. 87 (6), 600-604.

[47] Wang, Y. S., Liu, F. L., Jensen, L. S., de Neergaard, A., Jensen, C. R., 2013. Alternate partial root-zone irrigation improves fertilizer-N use efficiency tomatoes. Irrig. Sci. 31, 589-598. 